\title{
Invited review: Improving neonatal survival in small ruminants: science into practice
}

\author{
C. M. Dwyer ${ }^{1 \dagger}$, J. Conington ${ }^{1}$, F. Corbiere ${ }^{2}$, I. H. Holmøy ${ }^{3}$, K. Muri ${ }^{3}$, R. Nowak ${ }^{4,5,6,7}$, J. Rooke ${ }^{8}$, \\ J. Vipond ${ }^{9}$ and J.-M. Gautier ${ }^{10}$
}

\begin{abstract}
${ }^{1}$ Animal and Veterinary Sciences, Scotland's Rural College, King's Buildings, West Mains Road, Edinburgh EH9 3JG, UK; ${ }^{2}$ Ecole Nationale Vétérinaire, 23 Chemin des Capelles, 31300 Toulouse, France; ${ }^{3}$ Department of Production Animal Clinical Sciences, Faculty of Veterinary Medicine and Biosciences, Norwegian University of Life Sciences, PO Box 8146, Dep. N-0033 Oslo, Norway; ${ }^{4}$ INRA, UMR85 Physiologie de la Reproduction et des Comportements, F-37380 Nouzilly, France; ${ }^{5}$ CNRS, UMR7247, F-37380 Nouzilly, France, ${ }^{6}$ Université François Rabelais, F-37041 Tours, France; ' ${ }^{7}$ IFCE, F-37380 Nouzilly, France; ${ }^{8}$ Future Farming Systems, Scotland's Rural College, King's Buildings, West Mains Road, Edinburgh EH9 3JG, UK; ${ }^{9}$ SAC Consulting, Scotland's Rural College, King's Buildings, West Mains Road, Edinburgh
\end{abstract} EH9 3JG, UK; ${ }^{10}$ Institut de I'Elevage, Campus INRA, Chemin de Borde Rouge, 31321 Toulouse, France

(Received 1 May 2015; Accepted 11 August 2015; First published online 5 October 2015)

Neonatal mortality in small ruminant livestock has remained stubbornly unchanging over the past 40 years, and represents a significant loss of farm income, contributes to wastage and affects animal welfare. Scientific knowledge about the biology of neonatal adaptation after birth has been accumulating but does not appear to have had an impact in improving survival. In this paper, we ask what might be the reasons for the lack of impact of the scientific studies of lamb and kid mortality, and suggest strategies to move forward. Biologically, it is clear that achieving a good intake of colostrum, as soon as possible after birth, is crucial for neonatal survival. This provides fuel for thermoregulation, passive immunological protection and is involved in the development of attachment between the ewe and lamb. The behaviour of the lamb in finding the udder and sucking rapidly after birth is a key component in ensuring sufficient colostrum is ingested. In experimental studies, the main risk factors for lamb mortality are low birthweight, particularly owing to poor maternal nutrition during gestation, birth difficulty, litter size and genetics, which can all be partly attributed to their effect on the speed with which the lamb reaches the udder and sucks. Similarly, on commercial farms, low birthweight and issues with sucking were identified as important contributors to mortality. In epidemiological studies, management factors such as providing assistance with difficult births, were found to be more important than risk factors associated with housing. Social science studies suggest that farmers generally have a positive attitude to improving neonatal mortality but may differ in beliefs about how this can be achieved, with some farmers believing they had no control over early lamb mortality. Facilitative approaches, where farmers and advisors work together to develop neonatal survival strategies, have been shown to be effective in achieving management goals, such as optimising ewe nutrition, that lead to reductions in lamb mortality. We conclude that scientific research is providing useful information on the biology underpinning neonatal survival, such as optimal birthweights, lamb vigour and understanding the importance of sufficient colostrum intake, but the transfer of that knowledge would benefit from an improved understanding of the psychology of management change on farm. Developing tailored solutions, on the basis of adequate farm records, that make use of the now substantial body of scientific literature on neonatal mortality will help to achieve lower neonatal mortality.

Keywords: neonatal mortality, sheep, goat, knowledge transfer

\section{Implications}

Research into neonatal mortality of small ruminants has addressed relevant biological issues and provided practical solutions to some of the issues (such as improving ewe nutrition and ensuring adequate colostrum intakes). There is, however, more that could be done in transferring this information into practice, and application of social science

\footnotetext{
${ }^{\dagger}$ E-mail: Cathy.dwyer@sruc.ac.uk
}

methods to address barriers to uptake would be beneficial, as would improved record keeping on farm. Owing to the multifactorial nature of lamb survival, and differing risk factors on different farms, it is likely that individual farm-specific solutions would be required to achieve improved survival.

\section{Introduction}

The mortality of neonatal farmed livestock is a source of wastage, affects farm profitability, impacts on animal 
welfare and, frequently, farmer morale. Animals are most vulnerable on the day that they are born, with up to $50 \%$ of all pre-weaning mortality occurring on this day in sheep (Nowak et al., 2000) and goats (Singh et al., 2008). Newborns move from the warm and protected uterus into a more challenging extrauterine environment, which can occur in a cold or wet environment, where predators or other animals may behave aggressively towards the young animal. Thus, it is perhaps not surprising that mortality rates have proved remarkably stubborn and resistant to attempts to reduce them - published average mortality figures for sheep for the last 40 years across many countries and systems remain almost unchanging at $15 \%$ (Figure 1). Although fewer studies have been conducted in goats, published estimates of kid mortality range from $11.5 \%$ to $37 \%$ (e.g. Thiruvenkadan and Karunanithi, 2007; and Supplementary Material), suggesting that the scale of the problem is similar in both small ruminant species. However, there is significant between-farm variation with some farms able to reduce mortality to low levels. For example, on New Zealand sheep farms, mortality was reported to vary from $1.4 \%$ to $43.5 \%$ of all lambs in a survey of 22 farms (Forrest et al., 2006). Similarly, in goat farms in Tamil Nadu, India, annual mortality was reported to range from $2.2 \%$ to $30.5 \%$ (Thiruvenkadan and Karunanithi, 2007). Analysis of lamb mortality associated with disease led Fragkou et al. (2010) to suggest that lamb mortality should be as low as $3 \%$, with an upper acceptable limit of 5\%: a figure that is currently not achieved on many farms.

Considerable scientific knowledge about neonatal mortality has accumulated, but does not appear to have led to substantive reductions in lamb or kid losses. Lack of uptake or impact of this research may have occurred for several reasons: (1) many studies have characterised the causes of lamb mortality, but have not provided practical, on farm solutions to address these; (2) experimental studies may not adequately replicate the 'real' on farm environment and

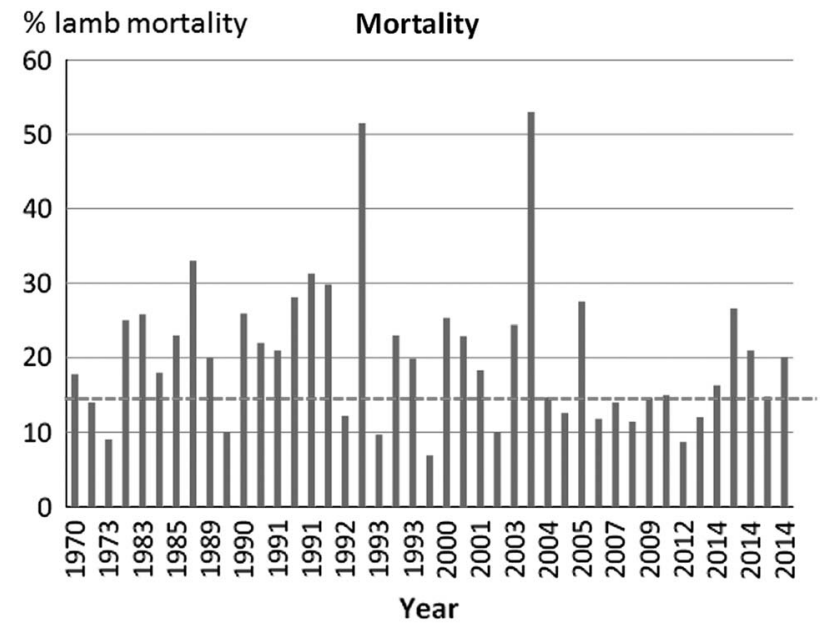

Figure 1 Published average percentage lamb mortality between 1970 and 2014 (references are given in the text and Supplementary Material) showing no improvement over 40 years. The dotted line represents an overall average mortality of $15 \%$. therefore may not provide relevant solutions; (3) scientific investigations have often concentrated on single issues or causal factors, when mortality is a complex interaction of many factors; (4) the scientific solutions may not have been properly communicated to farmers or other barriers, such as availability of affordable skilled labour, exist to prevent implementation on farm; or (5) improvements have been achieved but these have not been reported in the scientific literature. In this paper, we will address the reasons for the lack of impact of the scientific studies of lamb and kid mortality, and discuss how progress can be made. First, we will address the current scientific knowledge which may provide solutions that could be implemented on farm. Second, we will consider more practical applications of this knowledge on commercial farms and how readily these practices can be adopted to improve lamb survival.

\section{Biological factors involved in lamb and kid mortality/survival}

The causes of lamb mortality have been extensively researched. The overall consensus is that lamb mortality occurs due to: (1) birth trauma following a difficult or prolonged delivery that results in hypoxia and usually stillbirth; (2) development of a poor bond between the ewe and lamb that causes starvation and hypothermia in the lamb usually resulting in death on the day of birth; (3) infectious disease; and (4) a number of other relatively minor causes of mortality including congenital malformation, predation and accident (see references in Supplementary Materials). The relative prevalence of these causes of mortality will vary in different systems, for example, infectious disease may be higher in housed systems, but deaths from traumatic injury may be reduced as obstetric assistance can be provided more readily. In outdoor lambing systems, mortality from starvation, hypothermia or predation may be more important than infectious disease. Goats have been less well studied compared with sheep, and the available literature has tended to concentrate on traditional small-scale or village production environments (e.g. in West and South Africa, India, Middle East, Central and Southern America) rather than largerscale commercial production environments, which have been the focus of sheep studies. Nonetheless, the causes of kid mortality are very similar to those of lambs, although mortality owing to disease (neonatal infections, tick-borne or parasitic) appears to be more prevalent (e.g. Singh et al., 2008; and see Supplementary Material). Whether this is related to a greater susceptibility of goat kids to disease, or because, in the published studies, they are more likely to be exposed, and less likely to have been vaccinated against common infectious diseases affecting small ruminants (such as clostridial disease via dam vaccination), is not clear.

Risk factors for lamb mortality are also well described. Lamb mortality is higher in low birthweight lambs, lambs born in larger litters, lambs born to inexperienced or young mothers and in male lambs (e.g. Sawalha et al., 2007; and see Supplementary Material). Management factors relating 
to nutrition, breeding objectives, hygiene practices around lambing and management interventions can all contribute to the rate of lamb survival. Similar risks associated with birthweight, sex, parity and litter size have also been reported in goats, although season of birth is also a significant risk factor (e.g. Singh et al., 2008; and see Supplementary Material). As most studies are concentrated in tropical regions, seasonal effects (largely whether it is the rainy or dry season) are probably related primarily to nutritional influences, although level of parasites and pathogens may also be relevant.

The success with which the kid or lamb achieves the critical adjustments required to establish independent life after birth are influenced by interacting biological processes, outlined in Figure 2. Expulsion from the uterus at birth requires profound physiological adjustments: establishing pulmonary respiration, cardiovascular adjustment, loss of thermal insulation and placental nutrient supply, vigorous locomotor activity and coordination necessary to express teat-seeking behaviour, ingestion of colostrum and, consequently, gastrointestinal and metabolic adaptation, and the development of neonatal immunity.

The key physiological, behavioural and immunological challenges experienced by the neonate are discussed below, and the impact of nutritional and genetic factors on these interactions considered.

\section{Behaviour and neonatal survival}

Imminent parturition triggers a decreased social affiliation in the ewe who seeks a suitable place to give birth (see reviews; Dwyer and Lawrence, 2005; and Supplementary Material). Birth-site selection will determine the micro-environment in which the lamb will be born, and can potentially influence the success of lamb thermoregulatory responses (see below) if ewes select sheltered and protected birth sites. Wet, windy and cold weather are important factors in deaths of lambs from hypothermia (Alexander et al., 1980). In addition, time spent at the birth site is an important factor in preventing separation between ewes and lambs, thus selection of a birth site with features that will encourage the ewe

(a)

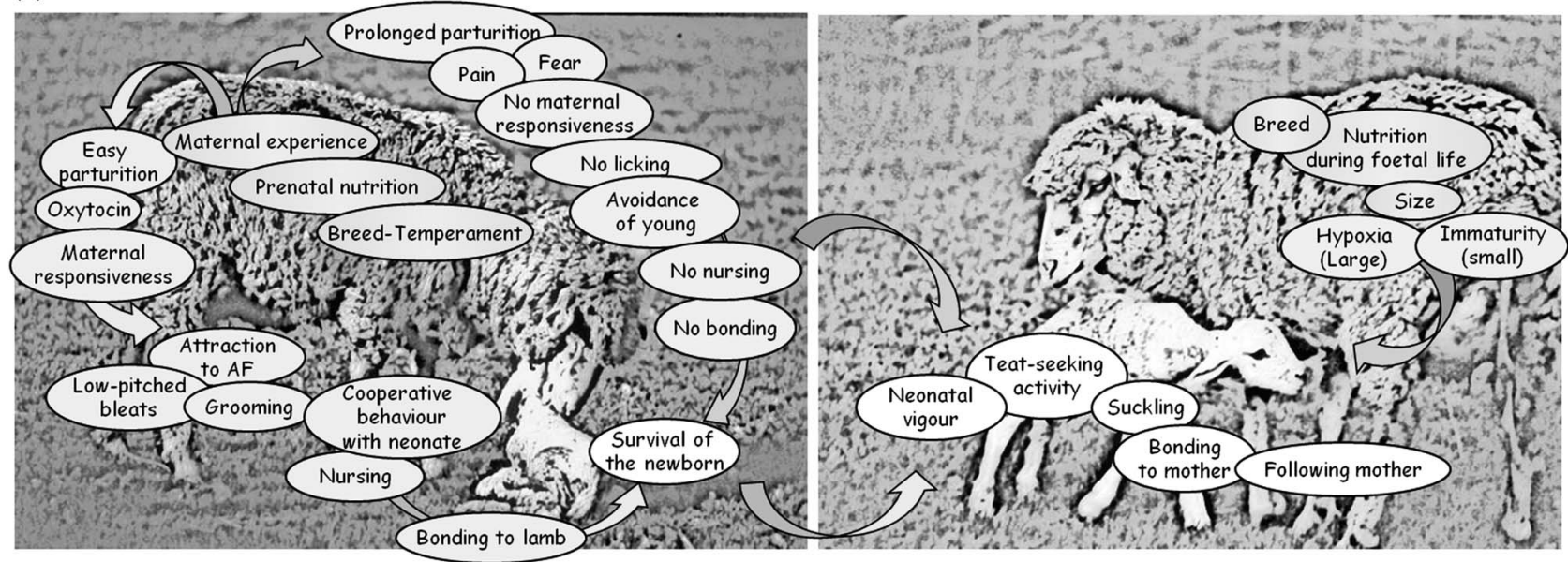

(b)

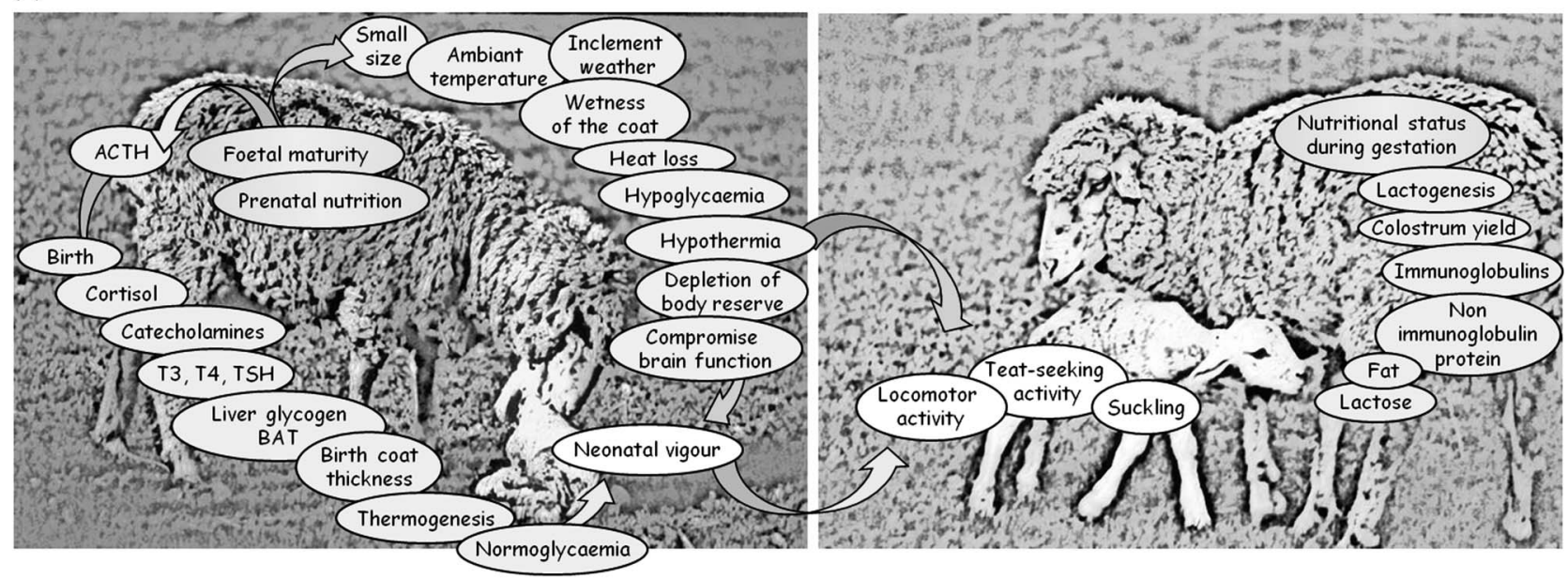

Figure 2 The complexity and risk factors influencing the interactions between ewe and lamb that affect lamb survival for (a) behaviour and (b) physiology. $\mathrm{AF}=$ amniotic fluid; $\mathrm{ACTH}=$ adrenocorticotrophic hormone; $\mathrm{T} 3=$ triiodothyronine; $\mathrm{T} 4=$ thyroxine; $\mathrm{TSH}=$ thyroid-stimulating hormone; BAT = brown adipose tissue. 
to remain at the site for a prolonged period can also influence survival.

Maternal behaviour of parturient ewes and goats is very similar (Poindron et al., 2007). During and immediately after birth ewes and goats are very attracted to the smell and taste of amniotic fluids, and will lick fluids that have been spilt during the birth process, transferring this attraction to the newborn. Maternal behaviour in the first few hours after delivery consists of focussed licking and grooming of the young, accompanied by frequent low-pitched bleats, and acceptance of the neonate at the udder. Licking or grooming serves to dry the offspring, and is important in the formation of an exclusive olfactory memory in the mother for her own neonates. This is established within an hour or so of giving birth, and the dam will then restrict her maternal care only to those offspring with which she has formed an exclusive attachment. Failure to develop this attachment will result in the mother not recognising the lamb or kid as her own and rejecting attempts by the neonate to access the udder and suck. As other lactating females will also reject the lamb or kid, these newborns will not survive without human intervention. Following olfactory recognition, mothers then learn to identify their lamb or kid via their visual appearance at a distance, and then by their vocalisations (Poindron et al., 2007).

Maternal behaviour by the ewe can facilitate lamb-sucking responses, by standing and making the udder more available to the teat-seeking lamb. Inexperienced ewes are less likely to cooperate with lamb-sucking attempts, initially, which may contribute to the reduced survival of the lambs of primiparous ewes. However, ewe behaviour alone cannot induce the lamb to suck, and separation of ewe and lamb behavioural effects by embryo transfer (Dwyer and Lawrence, 1999), suggests that maternal behaviour does not encourage greater vigour and vitality in her newborn lamb. Maternal attachment scores have a negligible correlation with lamb survival (Hatcher et al., 2010) and measures of maternal behaviour are also poorly genetically correlated with lamb survival (Brien et al., 2014), suggesting that variation in the quantity or quality of maternal behaviour expressed may not have a great influence on lamb survival.

In contrast, lamb behaviour is crucial in determining survival. At birth, lambs move through a series of behavioural events directed towards standing, udder seeking and sucking. Standing reduces heat loss to the ground, so helping the lamb to maintain body temperature, and the lamb then employs a series of reflex and coordinated responses to move along the body of the ewe and locate the udder. The speed with which the lamb accomplishes these behaviours is known to be related to its probability of survival (Dwyer et al., 2003). Moreover, lambs that derive from sires or lines of sheep with good survival are quicker to stand and suck than lambs from high loss lines or sires (Cloete and Scholtz, 1998; Hergenhan et al., 2014). Suckling quickly provides the lamb with nutrients, particularly to sustain thermoregulation, and immunoglobulins to provide passive immunity. In addition, suckling and ingestion of colostrum play a role in the development of attachment of the lamb for its mother (Goursaud and Nowak, 1999).

Lamb and kid behaviour is affected by many of the same risk factors that are associated with increased mortality. Behavioural development is impaired in lambs that have been delivered after a prolonged labour, in larger litters and in male lambs compared with female (Dwyer, 2003). Furthermore, lamb birthweight exhibits a U-shaped distribution with lamb vigour at birth in a similar way to lamb survival (Dwyer et al., 2003). Breed, line and sire within breed variation in lamb behaviour has been demonstrated in many studies (Cloete and Scholtz, 1998; Hergenhan et al., 2014; and see Supplementary Materials). The early vigour or sucking ability of lambs has been shown to have a moderate heritability (Matheson et al., 2012), suggesting that improving lamb vigour may be possible by genetic selection, which would lead to improved survival. Whether similar genetic relationships and phenotypic associations with survival exist for goat kid behaviour is not known.

\section{Physiology and neonatal survival}

At birth, ambient temperatures can drop from $39^{\circ} \mathrm{C}$ in utero to $10^{\circ} \mathrm{C}$ or lower. Maintenance of body temperature depends on the balance between heat loss and heat production. Heat loss is mainly affected by body surface area (small lambs have a higher surface area/BW ratio than large lambs, thus they lose heat faster and are more at risk of hypothermia) and the insulation value of the coat (short, fine birth coats have lower insulation value than long, coarse coats). A wet coat, by amniotic fluid, reduces insulation value but removal of the fluid by maternal licking or grooming contributes to the lamb's ability to maintain normal body temperature. Within 10 min of birth the lamb increases heat production but important inter-individual variations are observed (Dwyer and Morgan, 2006), and in the most extreme cases, where lambs are unable to generate sufficient heat, hypothermia is irreversible. Heat production comes from two main mechanisms in the neonate: non-shivering thermogenesis, mostly if not all attributable to brown adipose tissue, and shivering thermogenesis, which usually takes place under cold conditions, mainly in older, dry lambs, and metabolises muscle glycogen. Details of the thermogenic mechanisms employed by neonatal small ruminants are given in the Supplementary Material.

Colostrum contains nutrients, immunoglobulins and other elements such as enzymes, hormones, growth factors and neuroendocrine peptides. Colostrum contains fat $(7 \%$ to $13 \%)$, non-immunoglobulin protein ( $4 \%$ to $10 \%)$ and lactose $(2 \%$ to $5 \%$ ), and provides 6 to $7 \mathrm{~kJ}$ of energy/ml (Nowak and Poindron, 2006; Banchero et al., 2015). At $18^{\circ} \mathrm{C}$ to $26^{\circ} \mathrm{C}$, lambs require $50 \mathrm{ml}$ colostrum $/ \mathrm{kg}$ within the first $18 \mathrm{~h}$ of life to make up for lipid energy deficit and prevent hypothermia, at $0^{\circ} \mathrm{C}$ to $10^{\circ} \mathrm{C}$ requirements increase to $280 \mathrm{ml}$ colostrum $/ \mathrm{kg}$. Early ingestion of colostrum has an additional benefit in that it increases heat production by $17 \%$ even if body energy reserves are still replete, enhancing resistance to hypothermia. Under optimal conditions, neonates would consume sufficient 
colostrum to meet their carbohydrate requirement for $14 \mathrm{~h}$ of the first $24 \mathrm{~h}$ of life (Mellor and Cockburn, 1986). Utilisation of glycogen is therefore essential to make up the difference, and lambs face the first few days with largely depleted liver and muscle glycogen. Colostrum yield is dependant on adequate supplies of both energy and protein in the last 3 weeks of gestation. Although twin-bearing ewes generally yield more colostrum than single-bearing ewes, their onset of lactation is slower and they do not produce as much colostrum per lamb (Banchero et al., 2015). Thus, multiple-born lambs, compared with singles, are disadvantaged, in addition to lower birthweights and energy reserves, and higher surface area/BW ratios. Inadequate nutrition during gestation can delay the onset of lactogenesis, reduce colostrum and milk production, and affect colostrum viscosity (Banchero et al., 2015). As a consequence, delayed suckling may lead to energy reserves being exhausted within $6 \mathrm{~h}$ of birth and result in depressed heat production. Insufficient intake of colostrum is the second major factor affecting neonatal survival after body reserve depletion.

Late pregnancy is associated with a considerable rise in cortisol concentration in the lamb in the last 24 to $48 \mathrm{~h}$, as activation of the hypothalamic-pituitary-adrenal function triggers the birth process (Challis and Brooks, 1989). This results in high circulating cortisol, which may be responsible for vigorous locomotor activity and teat-seeking behaviour, as vaginal birth and concomitant stress hormones are associated with increased neonatal arousal (Lagercrantz and Slotkin, 1986). High plasma cortisol in lambs in the first postnatal hours prevents premature gut closure and therefore may enhance macromolecule absorption (Hough et al., 1990). The decline in cortisol concentration observed in the following days coincides with periods during which thyroid hormones increase as thermal efficiency improves and rectal temperature stabilises. The perinatal rise of cortisol is accompanied by an increase in triiodothyronine and thyroxine, which is maintained throughout early postnatal life. Thyroid hormones are known to play an important role in regulating oxygen consumption; failure to maintain high plasma triiodothyronine concentration results in a decrease in oxygen consumption, hypothermia and death (Symonds et al., 1995). However, the relationship of cortisol with survival is complex: alongside the beneficial effects of elevated neonatal cortisol, excessively high levels at birth may be related to difficult parturition and fatal dystocia, whereas an increase in circulating cortisol in the following days reflect a state of chronic stress owing to inadequate milk supply and is associated with elevated blood glucose to compensate for lack of nutrient intake (Chniter et al., unpublished).

Improved lamb viability beyond $72 \mathrm{~h}$ is associated with decreased vulnerability to chilling, singleton status, higher pre-suckling body temperature, decreased pre-suckling glucose concentrations, high plasma concentration of proteins, lipids and immunoglobulins, and a moderate rise in neonatal cortisol concentration (Eales et al., 1982; Miller et al., 2010). Being bigger is an advantage in terms of vigour and thermoregulation, as lambs are more efficient in their suckling activity and in resisting cold exposure. However, birthweight can be affected by breed (Slee, 1981; Dwyer and Morgan, 2006), season of birth (Chniter et al., 2013), variation within a litter or prenatal nutrition.

\section{Immune function and neonatal survival}

The ruminant placenta is epitheliochorial and does not allow the transfer of immune components from the mother to the young. Newborn lambs and kids are thus born markedly hypogammaglobulinaemic, and depend entirely on passive transfer of colostral immunoglobulins, acquired by suckling, for immunological protection after birth. Passive immunity must be acquired within a very narrow time window as, in newborn lambs, gut closure to immunoglobulin absorption occurs between 24 and $36 \mathrm{~h}$ after birth (Hough et al., 1990). However, colostral immunoglobulins also decline rapidly in the hours after birth, to virtually zero within $24 \mathrm{~h}$ of birth (Al Sabbagh et al., 1995), so early suckling is a prerequisite for effective transfer. Lamb mortality is associated with low immunoglobulin status $24 \mathrm{~h}$ after birth (Kenyon et al., 2005), demonstrating the importance of ensuring good colostrum intake in newborn small ruminants.

Adequate colostrum intake relies on two complementary factors: the ability of the lamb to ingest sufficient amounts (through vigorous sucking behaviour) and the concentration and quantities of colostral immunoglobulins available from the ewe. Partitioning the sources of variation in lamb serum immunoglobulin on farm suggests that $56 \%$ of the variation can be attributed to the lamb (e.g. volume ingested), $36 \%$ to the ewe and only $7 \%$ to the farm (Christley et al., 2003). Correlation between ewe colostral immunoglobulin concentrations and lamb serum immunoglobulin concentrations is generally low (McGuire et al., 1983), suggesting that other factors are important in ensuring good immunological protection for the offspring. Ensuring adequate sucking behaviour from the newborn, and cooperation from the dam, are therefore crucial to achieve adequate immunological protection. However, improving maternal immunoglobulin supply would also be beneficial. On farm data suggests that $22 \%$ of ewes produced $<50 \mathrm{~g} / \mathrm{limmunoglobulin} \mathrm{G}$ at lambing, which is considered inadequate to meet the needs of a lamb owing to its ingestion capacity. The considerable between-animal variation in the amount of $\mathrm{IgG}$ available in colostrum is affected by dam age (younger ewes produced more immunoglobulin), litter size, udder health, season of lambing in tropical regions and late gestational nutrition (Gilbert et al., 1988; and see Supplementary Material). There is some evidence for genetic factors influencing maternal colostrum immunoglobulin content with sire and breed effects reported, and a heritability of 0.19 for ewe immunoglobulin concentration in colostrum (Gilbert et al., 1988).

\section{Nutritional factors influencing neonatal survival}

Adequate nutrition of the ewe or goat during pregnancy is essential to produce viable offspring, which can thrive in the 
postnatal environment. Extensive research (see recent reviews for individual studies; Kenyon and Blair, 2014; Rooke et al., 2015) has described how changes in nutrition, both total and specific nutrient supply, impact on neonatal lamb characteristics relevant to survival. As, in temperate regions, the ewe is a seasonal breeder, and pregnancy in these climatic zones coincides with winter when nutrient availability from grazing is limited, an annual cycle approach to feeding the ewe has long been advised (Russell, 1985; Figure 3). Lactation, the period of maximum nutrient demand, normally occurs in spring when pasture growth and quality are at a maximum. After weaning lambs in mid/late summer, the ewe is able to replenish body reserves mobilised during gestation and lactation. Subsequently, deficits in feed nutrient supply, primarily energy, during gestation are balanced by mobilisation of adipose tissue. Thus, undernutrition (UN) is the nutrient imbalance most commonly encountered by the pregnant ewe. This imbalance is also seen in pregnant goats although, in tropical regions, this results from the annual cycle of rain and dry rather than day length as in temperate zones.

Maternal UN can influence neonatal lamb mortality in several ways. Directly, UN may reduce lamb birthweight and thereby increase mortality risk. Maternal UN can also adversely affect lamb neonatal behaviour and the ability of the lamb to thermoregulate. UN also influences mothering ability of the ewe, hence the establishment of the ewe-lamb bond (Dwyer et al., 2003), and the amount and quality of colostrum produced by the ewe. Similarly in goats, UN in the last third of gestation is associated with altered maternal care and impaired recognition abilities of mothers. However, the extent to which UN influences mortality through each of these routes has not been thoroughly investigated. Rooke et al. (2015) found, across all studies reviewed, that UN consistently reduced birthweight only in the last third of ovine pregnancy with the reduction in birthweight being related both to the length and severity of UN. In the first two-thirds of pregnancy, UN only reduced birthweight in specific circumstances. These included severity of UN:

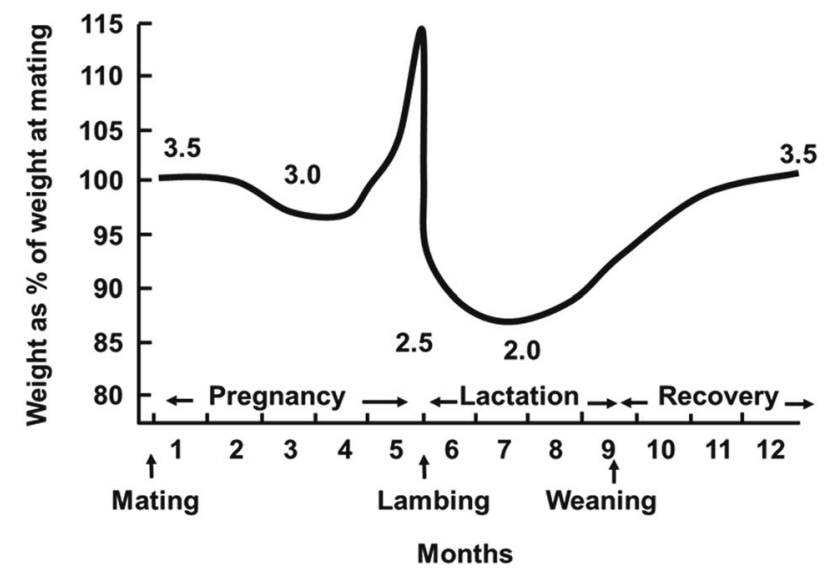

Figure 3 Illustration of the optimal changes in ewe weight (as a proportion of her weight at mating) during the reproductive cycle. Values given on the curve are indicative average body condition scores. feeding only 0.15 of requirement between gestation days 0 and 60 reduced birthweight and increased mortality. Breeds more adapted to adverse conditions (e.g. Scottish Blackface) partitioned more nutrients to the foetus and thereby maintained birthweight in response to early gestational UN challenge, whereas birthweight was reduced in breeds selected for more rapid growth (e.g. Suffolk). Ewes in good body condition were better able to withstand the challenge of UN than ewes in poorer body condition. Decreased birthweight, however, is only a risk factor for increased lamb mortality. Where both lamb birthweight and mortality were recorded (Rooke et al., 2015), in only half the studies was a decrease in birthweight accompanied by increased mortality. Contributory factors will be how large the decrease in birthweight was, the physical environment and the amount and quality of husbandry. Importantly, feeding the ewe nutrients in excess of requirements for foetal growth and ewe maintenance was not associated with improvements in lamb survival; in fact negative outcomes were more common than positive ones. This is supported by studies that show a U-shaped relationship between lamb birthweight and survival (Figure 4).

In relation to specific nutrients, most research has focussed on trace elements and vitamins where deficiency is a practical problem, and linked to increased mortality (e.g. deficiencies of copper, cobalt or iodine). Interpretation of many studies is difficult because the baseline status of ewes (deficient, marginal or adequate) before the study is frequently not well defined. Where the status of ewes was marginal, supplementation improved survival, or associated measures, for cobalt, selenium and vitamin $E$ (reviewed by Rooke et al., 2008). Responses where pre-experiment ewe status was adequate have been more equivocal and there is little evidence for any benefits to supplying trace nutrients in excess of requirement but short of toxicity (Rooke et al., 2008).

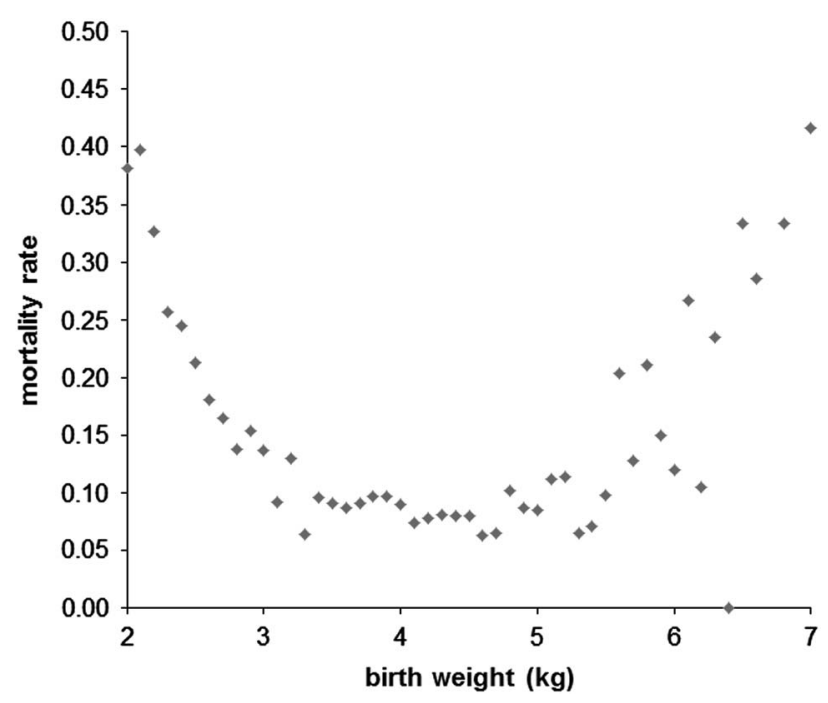

Figure 4 Relationship between lamb mortality rate (proportional mortality) and birthweight (in $\mathrm{kg}$ ) for Scottish Blackface lambs, demonstrating the optimal birthweight, for this breed, lies between 3 and $5 \mathrm{~kg}$. 
In summary, providing there are no chronic deficiencies in trace element and vitamin supply, UN is the main nutritional risk to neonatal lamb survival, particularly in the last trimester. As long as ewes have adequate body reserves at mating (Figure 3), loss of body condition over the first 100 days of pregnancy does not impose a markedly increased risk of lamb mortality. Where ewes are housed in late pregnancy, loss of body condition can be avoided by adequate feeding. Ewes kept outside on pasture are probably more at risk either from chronic UN from lack of grass growth or acute UN from adverse weather, for example, snowfall.

\section{Genetic aspects of neonatal survival}

Selecting for improved lamb survival both reduces 'wastage' while improving animal welfare, whereas selection for higher litter size inevitably increases lamb losses as lambs from multiple births have higher risk of mortality. Considering lamb survival 'as a trait of the lamb' in the context of a multitrait breeding index, is predicted to improve lamb survival at a faster rate than if it is considered as being a 'trait of the ewe' (Conington et al., 2002).

The heritability of lamb survival is generally low with most published estimates being <0.1 (e.g. Safari et al., 2005; Brien et al., 2014; and see Supplementary Material), although higher heritability estimates in experimental flocks have been documented (e.g. 0.13 to 0.33; Sawalha et al., 2007). Low heritability can in part be explained because farmers often do not record lambs born dead; and because the multifactorial nature of lamb mortality may mean that genetic variation in different causes of mortality may differ. Moreover, where flocks have a high degree of human intervention, lambs that would otherwise have died are often kept alive, thus the degree of human intervention may be an additional variable. It seems logical that extensively managed flocks, with low or no human intervention at the time of lambing, rely greatly on the expression of ewe and lamb behaviours that contribute to higher rates of survival. For these systems, the definition of the breeding goal can be relatively straightforward. Recent analyses (for details see Supplementary Material) for Scottish Blackface sheep estimate heritability for survival at 0.05 and 0.09 , with lamb birthweight being the most important predictor of survival.

The use of 'component' traits for lamb survival such as aspects of lamb vigour and ability to reach critical 'survival milestones' (e.g. sucking) have been suggested (Matheson et al., 2012). For farmers who are keen to reduce reliance on human intervention around lambing time and to identify families of more vigorous lambs, using such 'indicators' of propensity to have higher survival makes good sense. Unfortunately, the time required to implement some of the measures is prohibitive and so alternatives to behavioural observational milestones are preferable.

It is likely that the molecular basis to lamb survival is highly polygenic, that is, many different gene variants are involved in the complex biological mechanisms associated with survival. Some key mechanisms, such as ability to generate heat through non-shivering thermogenesis, have been described above and the genetic basis to cold resistance documented (also see Supplementary Material). There is evidence that a variant of the ovine $\beta 3$-adrenergic receptor gene (ADRB3) is associated with higher risk of cold-related mortality in Merino sheep in New Zealand (Forrest et al., 2006). However, when extended to 13 other NZ breeds and crosses, the frequency of that gene variant was low or nonexistent, suggesting that it may already have been selected against in the breeds tested. It also highlights the inherent risks associated with translating results of gene associations found for one breed to all genotypes. Gene discovery for specific components of lamb survival will continue although the application of genomic breeding values: integrating single nucleotide polymorphism data with good survival phenotypes with lamb birthweight is perhaps more realistic.

\section{Practical applications}

Can the scientific knowledge outlined above lead to practical solutions to lamb mortality? The critical role of birthweight as a risk factor for neonatal mortality has been emphasised throughout: lamb vigour, udder-seeking and thermoregulatory ability are impaired in low birthweight lambs, and heavy lambs are vulnerable to dystocia and birth injury. Thus, ensuring an optimal intermediate birthweight (within breed), rather than maximising birthweight, is a key goal to increase survival. This requires attention to detail in feeding ewes, some mechanism for checking that nutrition is optimal (such as regular body condition scoring or assessing circulating $\beta$-hydroxybutyrate), and use of ultrasound scanning to determine litter size to tailor nutritional strategies appropriately. However, the interacting factors of litter size and ewe age still make this difficult to achieve practically. Defining the intermediate weight as a breeding goal will also help to ensure neonatal birthweights are targeted correctly.

Neonatal hypothermia is a significant cause of lamb mortality in many environments. Although heat loss and heat production can be influenced by birthweight, lambs can also be protected by provision of shelter, particularly those that are born outdoors, to limit the impact of evaporative heat loss. Research has investigated the impact of type and placement of different shelters in lambing paddocks (Pollard, 2006; and see Supplementary Material), but the factors determining birth-site selection by ewes, and thus the likelihood of births occurring in shelter, has not received much attention. Familiarity with the terrain, such as may be achieved with set stocking, influences shelter use, which suggests that permanent structures, or temporary features that are introduced well before lambing, may increase their use. Providing a sufficient number of appropriate birth sites for flock size is also important to prevent contamination of preferred sites, and to minimise the likelihood of mismothering if maternal ewes are forced to lamb in close contact with one another.

An adequate intake of colostrum is a fundamental component of lamb survival. Many of the risk factors for lamb mortality (Figure 2) have their root in preventing or reducing the uptake of sufficient colostrum by the lamb. 
Although the biological impact of sucking colostrum on neonatal responses has not been fully elucidated, ensuring that neonatal ruminants gain access to the udder and ingest colostrum as soon as possible after birth is probably the single most important factor in their subsequent survival. Although some newborns may require the provision of supplementary colostrum, it is preferable for neonates to find the udder of their mother and suck themselves, if this can be achieved within a reasonable timescale (ideally within $2 \mathrm{~h}$ of birth). Lambs tube-fed colostrum are less active and are licked less frequently by their mothers in comparison with naturally suckled lambs (Garcia Gonzalez and Goddard, 1998), which may indicate disrupted bonding.

Although the genetic component to lamb survival may be small, or difficult to measure accurately, there is opportunity to improve lamb survival by genetic means. In addition, appreciation that birth difficulty can impair lamb behaviour and survival, and thus selecting sires on the basis of lambing ease, should also improve lamb survival.

\section{Farm and management influences affecting survival}

Most knowledge on lamb and kid mortality is from biological studies carried out on experimental farms. How this might be translated into management practices and how applicable it may be to the diverse production and farming systems for sheep and goats remains to be addressed. Participative studies, which directly involve farmers, or epidemiological studies can help to identify the needs of farmers for better control of neonatal mortality. Here we consider knowledge about farm practices and control points from a participative sheep farm study conducted in France, and epidemiological studies in a number of sheep-farming countries. Similar studies are not available for goat farms. These studies will address whether the same issues, risk factors and causes are apparent on farm as have been addressed in experimental studies. Neonatal lamb mortality differs considerably among flocks (Binns et al., 2002; Forrest et al., 2006; Holmøy et al., 2012), with variations between $0 \%$ and $20 \%$ seen between flocks. Flock mortality rates were strongly correlated between years (Binns et al., 2002; Holmøy and Waage, personal communication), suggesting that flock level risk factors are important.

\section{On farm data collection}

In France, a participative study generated detailed on farm knowledge from 'real farm' situations and disseminated best practice. Data were collected on farms using one of three different farming systems: one lambing period per year, pastoral system and accelerated system (three lambing in 2 years) to understand factors associated with lamb mortality (for details see Supplementary Material). Overall mortality was $13.4 \%$, but varied across farms from $3.6 \%$ to $31.2 \%$. Lamb mortality followed a similar pattern to experimental studies, with $54 \%$ of mortality occurring within the first 2 days of life. However, the farmers in the study felt that they had little or no ability to influence lamb mortality during this period, and had more control over mortality occurring after the first 2 days. The main causes of mortality were very small lambs or sucking problems, although a large number of mortalities were of unknown cause.

Farms were very variable in the distribution of risk factors for lamb mortality. However, the main risk factors regularly observed were: ewes lambing with low body condition scores and deficient selenium status (as defined by selenium concentration of $<60 \mu \mathrm{g} / \mathrm{l}$ in at least three ewes), impaired colostrum intake, poor hygiene in the lambing sheds and mixed flocks with lambs of different ages.

\section{Flock and management factors}

Intensive lamb rearing is associated with increased mortality (Binns et al., 2002), although deaths from stillbirths are reduced. For indoor flocks, lamb mortality rates are lower where there is continuous monitoring (Holmøy et al., 2012). Likewise, mortality is higher in larger flocks ( $>900$ lambing ewes; Binns et al., 2002). These authors suggest that the increased risk may not be related to flock size per se, but to the reduced supervision ewes in larger flocks might receive. The presence of a stockperson allows prompt assistance with cases of dystocia and reduces deaths associated with difficult births.

Active involvement to ensure sufficient colostrum intake improves lamb survival. However, flocks where tube feeding is routine had increased neonatal mortality compared with flocks where assistance with suckling was the routine intervention (Holmøy et al., 2012). These differences may be associated with the increased risk of infection with tube feeding, or the role of sucking in behavioural interactions as described above. Use of tube feeding may also be more frequent in flocks where neonatal mortality rates already are high.

Lambs managed indoors may be exposed to high pathogen burdens in the environment, especially during peak lambing. Providing new bedding for lambing pens daily influenced mortality rates in the first $24 \mathrm{~h}$ after birth, but not subsequently (Binns et al., 2002). Treating sick lambs with electrolytes was associated with low perinatal mortality rates, whereas fostering of lambs increased the risk (Binns et al., 2002). Fostering of lambs may be an indicator of a large proportion of multiple births in the flock, and thus the underlying reason for the increased risk observed. However, housing factors do not appear to be related to neonatal mortality, indicating that management practices should be the main focus when preventive flock level factors are addressed.

Taken together the participative study and epidemiological analyses suggest that on farm lamb mortality occurs for similar reasons as shown in the experimental work, and that similar risk factors are relevant. It should be emphasised that the studies described were predominantly in ewes housed at lambing time. Some of the practices described above as important determinants of lamb mortality rates may not be practical in other outdoor production systems. 


\section{Knowledge transfer: challenges and successes}

It is clear that there is considerable between-farm variation in neonatal mortality, and that the reasons for high mortality on one farm may not be the same on another. Although genetic solutions may be applicable across farms, for managementrelated actions (which are likely to be the main factors improving lamb mortality) there is no 'one' solution: individual farms may require individual solutions to address their own problems. In this section, we will consider point 4 of the introduction to discuss the issues around transfer of specific knowledge to farmers, and the barriers to uptake of this knowledge.

\section{Knowledge exchange}

Farmers acquire knowledge from many sources: written resources, farmer-focussed events, discussion groups and one-to-one interactions with advisors or veterinarians (Dodunski, 2014). Farmers consistently rate face-to-face interactions as their preferred means of acquiring knowledge (Ingram, 2008), and prefer activities involving practical and hands-on means of teaching (Dodunski, 2014). In a study of advisor-farmer interactions, Ingram (2008) characterised different types of knowledge exchange events and concluded that facilitative encounters, where the advisor and farmer worked together to address the situation, sharing their knowledge and experience, were the most effective in providing farmer education and development. This suggests that advisors or veterinarians are an important source of knowledge for farmers to improve lamb or kid survival, but the nature of this exchange can have an impact on the uptake and use of the information.

\section{Decisions regarding management change}

As research suggests that management practices are of greater importance than housing, improvements in neonatal lamb survival rates depend on changes in the farmers' decisions and behaviour. Many approaches to understanding decision making assume that the decision maker is only focussed on maximising profit, which may in fact not always be the case. Farmers, particularly on small farms, tend to value the way of life, independence and performance above expressive, social and instrumental aspects such as a high income (Gasson, 1973; Muri et al., personal communication).

The Theory of Planned Behaviour (Aizen, 1991) suggests that the immediate antecedent of behaviour is behavioural intention, which is under the influence of attitudes, subjective norms and perceived behavioural control. Attitude is the degree to which people evaluate something with favour or disfavour - in this case lamb mortality rates and the specific management procedures that may reduce them. Subjective norms are a person's perception of the extent to which important referents (e.g. other farmers, family members) would approve or disapprove of particular actions. Perceived behavioural control is a measure of the extent to which people believe they are able to control the outcome, for example, whether they actually think they can reduce lamb mortality through the suggested management change. In this regard, the results from the French participative study, which suggested that farmers felt they had little control over perinatal lamb mortality, are particularly interesting. Using this theory in a qualitative approach, Australian sheep farmers were shown to have a positive attitude to improving lamb survival rates, but differed in their beliefs about how to achieve this (Elliott et al., 2011). Social norms and perceived behavioural control played a significant role in decision making, and other farmers appear to be the most important referents. Furthermore, external factors such as type of farm, sheep breed, etc., also played an important role, as well as the characteristics of the farmers themselves (Elliot et al., 2011).

These data suggest that effective knowledge transfer of the increasing body of scientific research would be best achieved by one-to-one encounters, using a facilitative approach to explore the specific farm risk factors and derive workable farm-level solutions. This can help overcome factors, such as the apparent perception of lack of control over early lamb mortality, and may also be useful to challenge the perceived norms around neonatal mortality. The within-farm variation in mortality, which is observed in all studies that have gathered these data, provides evidence from commercial farms, rather than experimental studies, of what can be achieved. The process of improving on farm mortality may also be aided by collection of more specific data on farm, such as actual rather than estimated mortality rates and causes. Where this has been achieved, the rather pessimistic picture provided in the literature, that mortality rates have remained unchanged over the past 40 years can begin to be challenged.

\section{Success stories}

An example of successful facilitative knowledge exchange, conducted largely as small-scale discussion groups with a group of motivated farmers in the United Kingdom, has begun to deliver considerable benefits in terms of knowledge exchange and improvements in lamb mortality. Relevant to the discussions above about subjective norms are farmers that have chosen to move away from maximising lambing percentages (which might be viewed by other farmers as evidence of success but accompanied by higher losses) to achieve similar numbers of lambs weaned through a lower lambing percentage and lower mortalities. This more sustainable outcome might provide greater job satisfaction, without necessarily impacting on farm profitability.

Other successful examples include the uptake of behavioural and experimental information on the importance of lamb behaviour and its genetic components. Although these have not been used to derive breeding values for animals, improvements in lamb survival have been reported by culling or not re-breeding animals that have required assistance at lambing, where lambs required assistance to suck or where ewes have abandoned lambs. Similar strategies involve only selecting well-grown lambs from a group that produced and reared twins, thus selection is based on ability to rear two lambs rather than for litter size. 
Dwyer, Conington, Corbiere, Holmøy, Muri, Nowak, Rooke, Vipond and Gautier

On farm nutritional strategies that minimise the seasonal variation in ewe body condition have also been employed. Often these have not been prescriptive nutritional regimes, but are based on improved knowledge about the issues and costs to ewe and lamb survival of poor gestational nutrition, and then a workable solution derived that meets the needs of the individual farm to optimise the nutritional management of the flock. The advisor's role may have been to help the farmer to make decisions about behavioural change, as outlined above, to prioritise nutrition, and then helping to develop a solution that can be achieved on the farm.

Evidence for an improvement in lamb survival in these situations may often be anecdotal, or reported in trade papers, and may not have been published in scientific journals. However, farmers either culling or moving to different breeds are reporting improved shelter seeking by ewes (of woolshedding breeds), improved lamb thermoregulatory ability, and improved maternal care leading to better lamb survival.

\section{Conclusions}

At the start of this paper, we asked why the considerable amount of research on the causes of, and risks to, lamb mortality did not appear to have had an impact on improving lamb survival in practice, and suggested several reasons why this may have occurred. From a review of the data, we conclude that studies focussing on biological knowledge have produced a large body of information and that this can be used to develop practical solutions (point 1). It is true that experimental studies apply treatments in very controlled ways, with ethical endpoints, and may therefore underestimate impacts but the on farm studies quoted suggest that this has not tended to produce non-viable solutions or information that is not relevant to commercial situations (point 2). In addition, although experimental studies tend to only investigate a single factor at a time, the on farm data suggest that, first, these single issues may be those that are most important, and second, there may be farm-specific single issues that are the main contributors to mortality, thus a single issue solution may be the most useful (point 3 ). Thus, we can conclude that, even though experimental studies may not exactly replicate commercial farm environments, they do this sufficiently well to produce relevant data to assist with developing solutions on commercial farms.

It is possible that scientific information may not have been translated sufficiently well to farmers or others who provide on farm advice (point 4). The application of social science methods to understand barriers to uptake and the best means to deliver information is still relatively new and more could be done to facilitate this approach. In addition, many sheep farms still have relatively rudimentary record keeping of lamb mortality, and related data. Without this information, any progress will be very difficult to achieve. However, there is some evidence that improvements in lamb survival can be achieved where facilitative interactions take place between farmers and advisors, and clear management goals are present, although these improvements have not necessarily been reported in the scientific literature (point 5).

In conclusion, therefore, we suggest that neonatal survival in small ruminants can be improved on farm, and scientific knowledge of the biological issues can contribute to providing solutions. The large between-farm variation in lamb survival reported in many studies suggests that this can be achievable. However, it is clear that some farmers perceive that they have a lack of control over lamb mortality, and thus may not be motivated to attempt to improve survival, or have little knowledge of the level of lamb mortality on their farms as records are not kept. There will not be a single solution that will fit all farm systems, and determining the best practices to implement will need to be considered on a caseby-case basis. Education and training for advisors in the biological knowledge around lamb mortality, improved record keeping on farm, and advisory support for farmers in developing solutions that will work within their own farm systems, are key to achieving improved lamb survival.

\section{Acknowledgements}

This review is based on an invited presentation at the 65th Annual Meeting of the European Association for Animal Production held in Copenhagen, Denmark, August 2014.

\section{Supplementary material}

To view supplementary material for this article, please visit http://dx.doi.org/10.1017/S1751731115001974.

\section{References}

Additional references of relevance to this subject area are given in the Supplementary Material.

Ajzen I 1991. The theory of planned behaviour. Organizational Behavior and Decision Processes 50, 179-211.

Alexander G, Lynch JJ, Mottershead BE and Donnelly JB 1980. Reduction in lamb mortality by means of grass wind-breaks: results of a five-year study. Proceedings of the Australian Society for Animal Production 13, 329-332.

Al Sabbagh TA, Swanson LV and Thompson JM 1995. The effect of ewe body condition at lambing on colostral immunoglobulin-G concentration and lamb performance. Journal of Animal Science 73, 2860-2864.

Banchero GE, Milton JTB, Lindsay DR, Martin GB and Quintans G 2015. Colostrum production in ewes: a review of regulation mechanisms and of energy supply. Animal 9, 831-837.

Binns SH, Cox IJ, Rizvi S and Green LE 2002. Risk factors for lamb mortality on UK sheep farms. Preventive Veterinary Medicine 52, 287-303.

Brien FD, Cloete SWP, Fogarty NM, Greeff JC, Hebart ML, Hiendleder S, Hocking Edwards JE, Kelly JM, Kind KL, Kleeman DO, Plush KL and Miller DR 2014. A review of genetic and epigenetic factors affecting lamb survival. Animal Production Science 54, 667-693.

Challis JRG and Brooks AN 1989. Maturation and activation of hypothalamicpituitary adrenal function in fetal sheep. Endocrine Reviews 10, 182-204.

Chniter M, Hammadi M, Khorchani T, Ben Sassi M, Ben Hamouda M and Nowak R 2013. Aspects of neonatal physiology have an influence on lambs' early growth and survival in prolific D'man sheep. Small Ruminant Research 111, 162-170.

Christley RM, Morgan KL, Parkin TDH and French NP 2003. Factors related to the risk of neonatal mortality: birthweight and serum immunoglobulin concentrations in lambs in the UK. Preventive Veterinary Medicine 57, 209-226. 
Cloete SWP and Scholtz AJ 1998. Lamb survival in relation to lambing and neonatal behaviour in medium wool Merino lines divergently selected for multiple rearing ability. Australian Journal of Experimental Agriculture 38, 801-811.

Conington J, Bishop SC and Simm G 2002. Selection for sustainable UK hill sheep production. Proceedings of the 7th World Congress on Genetics Applied to Livestock Production, Montpelier, France. Communication no. 24-06.

Dodunski G 2014. Knowledge transfer to farmers. Small Ruminant Research 118 103-105.

Dwyer CM 2003. Behavioural development in the neonatal lamb: effect of maternal and birth-related factors. Theriogenology 59, 1027-1050.

Dwyer $C M$ and Lawrence $A B$ 1999. Does the behaviour of the neonate influence the expression of maternal behaviour in sheep? Behaviour 136, 367-389.

Dwyer CM and Lawrence $A B$ 2005. A review of the behavioural and physiological adaptations of extensively managed breeds of sheep that favour lamb survival. Applied Animal Behaviour Science 92, 235-260.

Dwyer CM, Lawrence AB, Bishop SC and Lewis M 2003. Ewe-lamb bonding behaviours at birth are affected by maternal undernutrition in pregnancy. British Journal of Nutrition 89, 123-136.

Dwyer CM and Morgan CA 2006. Maintenance of body temperature in the neonatal lamb: effects of breed, birth-weight, and litter size. Journal of Animal Science 84, 1093-1101.

Eales FA, Murray L and Small J 1982. Effects of feeding ewe colostrum, cow colostrum or ewe milk replacer on plasma glucose in newborn lambs. Veterinary Record 11, 451-453.

Elliott J, Sneddon J, Lee JA and Blache D 2011. Producers have a positive attitude toward improving lamb survival rates but may be influenced by enterprise factors and perceptions of control. Livestock Science 140, 103-110.

Forrest RH, Hickford JGH, Wynyard J, Merrick N, Hogan A and Frampton C 2006. Polymorphism at the ovine $\beta 3$-adrenergic receptor locus of Merino sheep and its association with lamb mortality. Animal Genetics 37, 465-468.

Fragkou IA, Mavrogianni VS and Fthenakis GC 2010. Diagnostic investigation of cases of deaths of newborn lambs. Small Ruminant Research 92, 41-44.

Garcia Gonzalez S and Goddard PJ 1998. The provision of supplementary colostrum to newborn lambs: effects of post-natal lamb and ewe behaviour. Applied Animal Behaviour Science 61, 41-50.

Gasson R 1973. Goals and values of farmers. Journal of Agricultural Economics 24, 521-542.

Gilbert RP, Gaskins CT, Hillers JK, Parker CF and McGuire TC 1988. Genetic and environmental factors affecting immunoglobulin $\mathrm{G} 1$ concentration in ewe colostrum and lamb serum. Journal of Animal Science 66, 855-863.

Goursaud AP and Nowak R 1999. Colostrum mediates the development of mother preference by newborn lambs. Physiology and Behavior 67, 49-56.

Hatcher S, Eppleston J, Thornberry KJ and Watt B 2010. High Merino weaner survival rates are a function of weaning weight and positive post-weaning growth rates. Animal Production Science 50, 465-472.

Hergenhan RL, Hinch GN and Ferguson DM 2014. Sire effects on neonatal lamb vigour and following-behaviour. Animal Production Science 54, 745-752.

Holmøy IH, Kielland C, Stubsjøen SM, Hektoen L and Waage S 2012. Housing conditions and management practices associated with neonatal lamb mortality in sheep flocks in Norway. Preventive Veterinary Medicine 107, 231-241.

Hough RL, McCarthy FD, Thatcher CD, Kent HD and Eversole DE 1990. Influence of glucocorticoid on macromolecular absorption and passive immunity in neonatal lambs. Journal of Animal Science 68, 2459-2464.
Ingram J 2008. Agronomist-farmer knowledge encounters: an analysis of knowledge exchange in the context of best management practices in England. Agriculture and Human Values 25, 405-418.

Kenyon P and Blair H 2014. Foetal programming in sheep - effects on production. Small Ruminant Research 118, 16-30.

Kenyon PR, Stafford KJ, Morel PCH and Morris ST 2005. Does sward height grazed by ewes in mid- to late-pregnancy affect indices of colostrum intake by twin and triplet lambs? New Zealand Veterinary Journal 53, 336-339.

Lagercrantz $\mathrm{H}$ and Slotkin TA 1986. The 'stress' of being born. Scientific American 254, 100-107.

Matheson SM, Bünger L and Dwyer CM 2012. Genetic parameters for fitness and neonatal behavior traits in sheep. Behavior Genetics 42, 899-911.

McGuire TC, Regnier J, Kellom T and Gates NL 1983. Failure in passive transfer of immunoglobulin-G1 to lambs - measurement of immunoglobulin-G1 in ewe colostrum. American Journal of Veterinary Research 44, 1064-1067.

Mellor DJ and Cockburn F 1986. A comparison of energy metabolism in the newborn infant, piglet and lamb. Quarterly Journal of Experimental Physiology 71, 361-379.

Miller DR, Blache D, Jackson RB, Downie EF and Roche JR 2010. Metabolic maturity at birth and neonate lamb survival: association among maternal factors, litter size, lamb birth-weight, and plasma metabolic and endocrine factors on survival and behavior. Journal of Animal Science 88, 581-593.

Nowak R and Poindron P 2006. From birth to colostrum: early steps leading to lamb survival. Reproduction, Nutrition, Development 46, 431-446.

Nowak R, Porter RH, Lévy F, Orgeur P and Schaal B 2000. Role of mother-young interactions in the survival of offspring in domestic mammals. Reviews of Reproduction 5, 153-163.

Poindron P, Levy F and Keller M 2007. Maternal responsiveness and maternal selectivity in domestic sheep and goats: the two facets of maternal attachment. Development Psychobiology 49, 54-70.

Pollard JC 2006. Shelter for lambing sheep in New Zealand: a review. New Zealand Journal of Agricultural Research 49, 395-404.

Rooke JA, Arnott G, Dwyer CM and Rutherford KMD 2015. The importance of the gestation period for welfare of lambs: maternal stressors and lamb vigour and wellbeing. Journal of Agricultural Science 153, 497-519.

Rooke JA, Dwyer CM and Ashworth CJ 2008. The potential for improving physiological, behavioural and immunological responses in the neonatal lamb by trace element and vitamin supplementation of the ewe. Animal 2 , 514-524.

Russell AJF 1985. Nutrition of the pregnant ewe. In Practice 7, 23-29.

Safari E, Atkins KD, Fogarty NM and Gilmour AR 2005. Analysis of lamb survival in Australian Merino. Proceedings of the Association for the Advancement of Animal Breeding and Genetics 16, 28-31.

Sawalha RM, Conington J, Brotherstone S and Villanueva B 2007. Analyses of lamb survival in Scottish Blackface sheep. Animal 1, 151-157.

Singh MK, Rai B and Sharma N 2008. Factors affecting survivability of Jamunapari kids under semi-intensive management system. Indian Journal of Animal Sciences 78, 178-181.

Slee $J$ 1981. A review of genetic aspects of survival and resistance to cold in newborn lambs. Livestock Production Science 8, 419-429.

Symonds ME, Bird JA, Clarke L, Gate JJ and Lomax MA 1995. Nutrition, temperature and homeostasis during perinatal development. Experimental Physiology 80, 907-940.

Thiruvenkadan AK and Karunanithi K 2007. Mortality and replacement rate of tellicherry and its crossbred goats in Tamil Nadu. Indian Journal of Animal Sciences 77, 590-594. 